Son, G.E. van, Hoeken, D. van, Furth, E.F. van, Donker, G.A., Hoek, H.W. Course and outcome of eating disorders in a primary care-based cohort. International Journal of Eating Disorders: 2010, 43(2), 130-138

\begin{tabular}{|l|l|}
\hline $\begin{array}{l}\text { Postprint } \\
\text { version }\end{array}$ & 1.0 \\
\hline $\begin{array}{l}\text { Journal website } \\
\text { Pubmed link }\end{array}$ & $\underline{\text { http://www3.interscience.wiley.com/journal/122266920/abstract }}$ \\
\hline DOI & $\underline{\text { http:/www.ncbi.nlm.nih.gov/pubmed/19308996 }}$ \\
\hline
\end{tabular}

This is a NIVEL certified Post Print, more info at http://www.nivel.eu

\title{
Course and Outcome of Eating Disorders in a Primary Care-Based Cohort
}

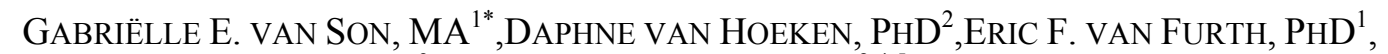
GÉ' A. DONKER, MD, PHD 3 , HANS W. HOEK, MD, PHD ${ }^{2,4,5}$.

${ }^{1}$ Center for Eating Disorders Ursula, Leidschendam, The Netherlands

${ }^{2}$ Parnassia Bavo Psychiatric Institute, The Hague, The Netherlands

${ }^{3}$ Netherlands Institute for Health Services Research, Utrecht, The Netherlands

${ }^{4}$ Department of Psychiatry, Groningen University Medical Center, Groningen, The Netherlands

${ }^{5}$ Department of Epidemiology, Columbia University, New York, New York

"Correspondence to: G. van Son, Center for Eating Disorders Ursula, Post Office Box 422, 2260 AK Leidschendam, The Netherlands. E-mail: g.vanson@centrumeetstoornissen.nl

\begin{abstract}
Objective: To study the course and outcome of patients with eating disorder detected in primary care.

Method: General practitioners (GP's) provided information on the course and outcome of eating disorders in patients $(n=147)$ diagnosed with anorexia nervosa (AN) or bulimia nervosa (BN) identified during a Dutch nationwide primary care-based incidence study. The research team determined the outcome based on the data provided by the GP's. The mean duration of the follow-up was 4.8 years.
\end{abstract}

Results: About $57 \%$ of the patients initially diagnosed with AN and $61 \%$ of those diagnosed with $\mathrm{BN}$ were fully recovered. AN binge/purge subtype (ANBP) demonstrated the most extended median survival time of all diagnostic subgroups (the point at which half of the group has reached full recovery). Diagnostic crossover was low. A younger age at detection predicted recovery at outcome for AN and BN. One patient (AN) died.

Discussion: The results of this study on differences in outcome and low crossover support the diagnostic distinction between AN and BN in the DSMIV. Early detection is of major importance for a favorable outcome.

\section{INTRODUCTION}

Numerous follow-up studies on eating disorders have been published. Reviews of these studies confirm that patients who suffer from anorexia nervosa (AN) have high mortality rates, ${ }^{1,2}$ moderate recovery rates, and a substantial proportion of the patients remain chronically ill. ${ }^{3,4}$ For patients treated for bulimia nervosa (BN), the long term recovery, chronicity, and mortality rates are more favorable. ${ }^{5,6}$ Virtually, every follow-up study on 
Son, G.E. van, Hoeken, D. van, Furth, E.F. van, Donker, G.A., Hoek, H.W. Course and outcome off eating disorders in a primary care-based cohort. International Journal of Eating Disorders: 2010, 43(2), 130-138

eating disorders made use of a patient sample that consisted of patients that were treated in specialized psychiatric settings. This limits the generalizability of these outcome studies ${ }^{7}$ because only a small percentage of patients with eating disorder, ${ }^{8}$ presumably those with more severe eating disorder symptoms, ${ }^{9-11}$ are being treated in (specialized) psychiatric settings. This implies that mainly there is outcome information available about a highly selected subgroup of patients with severe eating disorder symptoms. A recent report on the outcome of a sample that was detected at the community level supports this vision. In this study, the course and outcome of patients with AN showed a 5-year recovery rate of $67 \%,{ }^{12}$ which is much higher than the mean recovery rate of $47 \%$ found in samples of patients detected in (specialized) psychiatric treatment settings. ${ }^{3}$ To our knowledge, no information is available on the course and outcome of patients with an incident eating disorder detected in primary care. This study was intended to fill this informational gap. The sample consisted of newly diagnosed patients with an eating disorder (DSM-IV) detected at the primary care level during two data collection periods in the 80's and the 90's and can be considered as representative for the Dutch population. It is a patient sample that contains older and younger patients, males and females, and patients that did and did not receive treatment.

Our research aims were to (1) describe the course and outcome of eating disorders newly diagnosed at the primary care level, (2) examine differences in remission rates among the diagnostic (sub)groups and among different eating disorder symptoms, and (3) identify factors predictive of outcome at follow- up.

\section{METHOD}

This study was a follow-up of a group of patients with an eating disorder identified in a nationwide primary care-based study on the incidence of eating disorders in the Netherlands. During the incidence study, the Continuous Morbidity Registration Sentinel Stations (a network of general practitioners (GP's), managed by NIVEL, the Netherlands Institute for Health Services Research), ${ }^{13}$ recorded the number of new cases of a predetermined set of illnesses. During two 5-year periods P1: 1985-1989 and P2: 1995-1999, this nationwide network of, on average (calculated over the two periods) 63 GP's, registered the number of patients with eating disorder in their practices.

Every year, the participating GP's received detailed information on eating disorders by means of a circular and at an annual meeting. Of the GP's who participated in 1985, 53\% (N 531 ) participated for the full term of both study periods.

In the Netherlands GP's, medical doctors that have specialized in family medicine play a central role in the health care system and function as the "gatekeepers" to specialized care. Even if an individual contacts a specialist directly, the GP is always notified because health care insurers do not compensate for specialized health care costs without a written referral from the GP. Health insurance is virtually universal in the Netherlands: between 1990 and $1999,98 \%$ of the total Dutch population had health insurance. ${ }^{14}$ During P1 (1985-1989), the participating GP's together had an average annual patient load of 148,326 people $(\approx 1 \%$ of the average Dutch population during that period). During P2 (1995-1999), the annual average patient load was 149,797 people (again, $\approx 1 \%$ of the average Dutch population during that period). Both populations under study were representative of the total Dutch population for age, sex, region, and degree of urbanization. ${ }^{13,15,16}$ With the use of case identification criteria, based on DSM-III-R criteria (described in the appendix of the previous report ${ }^{17}$ ), the participating GP's considered whether each patient who consulted them might be suffering from AN or BN. To insure consistency, the same case identification criteria were used in both study periods, and the same information on eating disorders was provided to the GP's. For each possible patient with an eating disorder, the GP filled out an information sheet regarding eating disorder symptoms, height, weight, comorbidity, and referrals to specialized health care. The date of first diagnosis was also noted. The research team made the DSM-IV diagnosis on the basis of the information provided by the GP's. If 
Son, G.E. van, Hoeken, D. van, Furth, E.F. van, Donker, G.A., Hoek, H.W. Course and outcome of eating disorders in a primary care-based cohort. International Journal of Eating Disorders: 2010, 43(2), 130-138

necessary, the GP was asked to provide additional information. During both study periods, the same psychiatrist (author HWH) was responsible for making the final diagnoses. This study is a follow- up of newly detected patients with eating disorder during 1985-1989 and 1995-1999. At follow-up, GP's were asked to provide information about these patients after each data collection period (in 1991-1992 and 2001-2002, respectively). They were asked to fill out a data sheet about eating disorder symptoms during the follow up period and current health status for each patient identified in the incidence study. If the GP no longer treated the patient, the new GP was contacted whenever possible.

In case of nonresponse, the GP's received two written reminders. Thereafter, we contacted the GP by phone.

\section{Sample}

A total of 227 questionnaires about the patients with eating disorder identified in the incidence study were sent to the GP's: 126 in the first data collection period, and 101 in the second data collection period (see Fig. 1).

Of these, 217 related to unique persons: 10 patients were included twice. The information available for one patient was insufficient for the GP to identify the case again. The response calculations were therefore based on the remaining 216 cases. In 28 cases (13\%), the GP did not return the questionnaire after a second reminder (non-response).

In 28 other cases (13\%), the GP responded that the patient had switched GP and could not be traced.

In seven cases, the questionnaires were returned without information on outcome. In these cases, the GP could not provide information on the patient, most often because the patient was new in the practice or because the patient had not visited the GP for several years. In 2008, we again contacted these GP's by phone. This increased the response rate because in two out of seven cases, the GP's were now able to provide information on the patient. We also contacted the GP's of patients with a follow-up duration of less than 3 years and who were not recovered within this period. In three out of these 11 cases, new information prolonged the follow-up duration.

In line with the previous data collection, we set the maximum follow-up duration at 7.5 years. In total, 155 questionnaires (72\%) could be used for further analyses; 125 were completed fully; in 30 cases, the GP could provide only partial information. This affected the outcome of $\mathrm{BN}$ because in eight cases (11\%) the outcome remained unknown. The response percentages per diagnostic subgroup were anorexia nervosa restrictive subtype (ANR), 67\%; anorexia nervosa binge/purge subtype (ANBP), 80\%; and BN (69\%).

\section{[FIGURE1]}

Information provided by the GP's at follow-up was also used to validate the baseline DSMIV diagnosis. In one case, the GP indicated that, in retrospect, there never had been an eating disorder. In three cases, the follow-up data led us to conclude that the initial case report should not have been considered as incident, and in four cases $(\mathrm{AN}=1$ and $\mathrm{BN}=3)$, the follow-up information caused us to change the diagnosis at baseline to eating disorder not otherwise specified (EDNOS). Thus, all further analyses were performed on 147 cases, which were retrospectively validated as $\mathrm{AN}$ or $\mathrm{BN}$ at baseline (Table 1).

\section{Follow-Up Duration}

The follow-up period varied and ranged between 1 and 7.6 years $(n==144)$. The mean $( \pm \mathrm{SD})$ duration of follow-up was $4.8 \pm 1.6$ years, the median was 4.7 years. In three cases, the GP was unable to provide the moment the patient had left the practice and therefore information on follow-up duration was missing. In three cases, the duration of follow-up was less than 2 years. This was because the patient had relocated, so the GP filled out the questionnaire based on the situation at the last consultation. 
Son, G.E. van, Hoeken, D. van, Furth, E.F. van, Donker, G.A., Hoek, H.W. Course and outcome off eating disorders in a primary care-based cohort. International Journal of Eating Disorders: 2010, 43(2), 130-138

\section{Clinical Variables}

The GP's provided information about the current height and weight, number of binge eating episodes per week, duration of binge eating (in months), current menstrual status (multiple choice question with answer possibilities "oral contraceptives," "regular menses after amenorrhea," "regular menses," "irregular menses," “amenorrhea not caused by eating disorder," "amenorrhea, if yes, specify duration in months"). For purging behaviors (selfinduced vomiting and laxative use), the GP's stated if the behavior had been present in the follow- up period and if so, the GP's were asked to state the frequency and the years the behavior was present. Age at detection and sex were included in the analyses as demographic data. Information about age at onset was not available to us as we used a study method in which the GP's screened and provided information on the eating disorders symptoms.

Reliable assessment of age at onset requires patient interviews. Other demographic variables, that is, living situation, occupation of the patient and parents, and educational level yielded too much missing information because this nonmedical information was not always known to the GP.

\section{[TABLE 1].}

\section{Outcome}

For each diagnostic group, the outcome was divided into three categories (good, intermediate, and poor). To facilitate survival analyses, the outcome was further dichotomized into "clinically recovered" and "not clinically recovered." To make this division, the categories "intermediate" and "poor" were merged into the category "not clinically recovered." We used a three-stage method to determine the outcome for each patient. First, the objective data (BMI, data about the presence of binge eating, selfinduced vomiting, and use of laxatives) were used to construct a provisional outcome. In line with studies about the usefulness of amenorrhea as criterion for the diagnosis anorexia nervosa, ${ }^{18}$ ${ }^{22}$ the menstrual status was taken into account when there was no data on BMI. The presence of amenorrhea was considered as an indication of being underweight. With regard to bingeing and purging behaviors, we asked the GP's to provide the years during which binge eating, self-induced vomiting, and laxative use were recorded. The GP's also stated if and when (what year) the eating disorder of the patient had improved.

In the second stage, the current diagnosis and judgment about improvement provided by the GP was compared with the provisional outcome. If the two corresponded, the outcome was finalized. If there was no correspondence, the outcome of the particular case was discussed in a consensus meeting in which three eating disorder experts ( $\mathrm{HWH}, \mathrm{DvH}, \mathrm{GvS}$ ) participated. A case was also discussed in the consensus meeting if there was too little objective information available. All other information the GP had provided was then used such as written information, demographic data, and information from other health care professionals. In total, 16 cases were discussed in the consensus meeting. In 10 cases (of which eight had a baseline diagnosis of $\mathrm{BN}$ ), we had too little information, and the outcome remained unknown.

In the survival analyses, these cases were only taken into account in the year at detection. For ANR and ANBP, good outcome was defined as having a BMI of 19 or higher and no binge eating behaviors nor purging behaviors present. This BMI cut-off point is used in clinical samples ${ }^{4,23}$ as well as in population based samples. ${ }^{12}$ Poor outcome was defined as having a BMI below 17.60. Within this weight category, the presence of purging and/or binge eating behaviors at follow-up distinguished between the diagnoses ANR or ANBP. When a patient had died, the outcome was considered as poor. Patients with AN with an intermediate outcome had a BMI between 17.6 and 18.99 with or without binging and/or purging behaviors. Some of the patients with $\mathrm{AN}$ with an intermediate outcome met the criteria for EDNOS or BN at follow-up. For the patients initially diagnosed with BN, good outcome was defined as engaging in neither binge eating nor purging behaviors. Poor 
Son, G.E. van, Hoeken, D. van, Furth, E.F. van, Donker, G.A., Hoek, H.W. Course and outcome off eating disorders in a primary care-based cohort. International Journal of Eating Disorders: 2010, 43(2), 130-138

outcome was defined as having a combination of binge eating and engaging in compensatory behaviors, and the patient was given a BN diagnosis at outcome. Possible AN diagnoses were considered poor outcome. Intermediate outcome was defined as meeting either binge eating or compensatory behaviors (categorized as EDNOS). Also patients whom the GP considered as improved but not recovered fell into the category intermediate.

\section{Statistical Analyses}

Differences between diagnostic subgroups on baseline variables were analyzed using oneway analyses of variance (ANOVA) with post hoc Tukey's HSD tests. To check if the cases on which follow-up data were available represented the total sample, we compared several baseline variables (BMI, age at detection, referral to mental health care, and frequency of binge eating) per diagnostic subcategory for patients with and without follow-up data.

BMI and frequency of binge eating for severity of core symptoms of eating disorders. Age at detection was chosen because the incidence of eating disorders is highest in an age range with a high mobility rate. ${ }^{24} \mathrm{We}$ checked if this mobility had influence on the representativeness of our final sample. Referral to mental health care was analyzed because the referred patients might suffer from more severe eating disorders compared with those that were not referred. We used independent $t$-tests or ANOVA tests for continuous variables and Pearson chi-square $\left(X^{2}\right)$ for dichotomized variables. All alpha levels were set at $\mathrm{p}<05$ using two-tailed significance tests, if not otherwise stated.

The median survival time, the time at which $50 \%$ of the sample has experienced the outcome, was calculated by means of life tables for the year of recovery (as determined by the GP) and for remission of eating disorder symptoms. This was calculated for the whole sample and per diagnostic group. The Mantel-Cox Log Rank test was used to check the null hypothesis that there was no difference between the survival curves of the diagnostic subgroups. We checked if the variability in duration of follow-up influenced the results by analyzing if the duration of follow-up served as a prognostic factor for the dichotomous outcome "recovery" and "no recovery." This was analyzed separately for AN and BN. In the logistic regression analyses, duration of follow-up was no prognostic factor for outcome.

Possible prognostic factors were investigated with logistic regression analyses. The outcome was dichotomized and defined as "recovered" and "not recovered." In line with other studies, $3,25,26$ the following prognostic variables for AN or BN outcome were examined: age at detection (19 years and younger versus 20 years and older), duration of follow-up (14.9 years of follow-up versus 5 years and more), and severity of the disorder.

The division in age at detection was made because incidence studies show that the peak incidence lies between 15 and 19 years old and furthermore, it also marks the ending of adolescence and beginning of adulthood. For duration of follow-up, the division was made at 5 years, because this point is approximate to the median follow-up duration and it concurs with other follow-up studies. ${ }^{12,26-28}$ In AN, BMI at detection was used as a proxy for severity of the disorder; it was categorized as very severely underweight (BMI 14.9 and lower), severely underweight (BMI 15-17.5), and underweight (BMI 17.6- 19.5). In BN, the frequency of binge eating per week was used as a proxy for severity of the disorder; it was divided into three categories (1-2, 3-7, and $>8$ times a week).

Both severity indicator variables were divided according to clinical severity marks. The effect of gender could not be investigated because there were too few males in the sample. All possible predictors were entered in the regression analyses as categorized variables because none of the predictors demonstrated a linear correlation with the outcome variable. 
Son, G.E. van, Hoeken, D. van, Furth, E.F. van, Donker, G.A., Hoek, H.W. Course and outcome of eating disorders in a primary care-based cohort. International Journal of Eating Disorders: 2010, 43(2), 130-138

\section{RESULTS}

\section{Representativeness}

\section{[TABLE 2].}

For each diagnostic group, we compared if the baseline data on BMI, age at detection, referral to mental health care, frequency of binge eating (not compared for ANR) differed between the groups with and without available follow-up data. None of these variables showed significant differences for ANR and ANBP. However, for the BN groups, there was a difference in BMI. The group for which follow-up data were available had a higher mean BMI at baseline (29.3 versus 25.3; $\mathrm{t}=2.135, \mathrm{df}=90, \mathrm{p}=.035)$.

\section{Course and Outcome Per Diagnostic Subgroups}

The outcome per diagnostic subgroup is shown in Table 2.

In total, $57 \%$ of the AN group and $61 \%$ of the BN group were clinically recovered. At follow-up, $17 \%$ of the ANR group still met the initial diagnostic criteria.

No crossover to other diagnostic subgroups was found. Twenty three percent of the ANBP group still met the diagnostic criteria for ANBP, $6 \%$ now met diagnostic criteria for BN, and another $6 \%$ crossed over to the diagnosis EDNOS (including one case of binge eating disorder (BED)). In the initial BN group, 6\% still met the diagnostic criteria for this disorder at follow-up, and 20\% met the criteria for EDNOS, including 11 cases of BED. No crossover was found to either of the AN subgroups.

The mean BMI's for the ANR and ANBP subgroups at outcome were significantly higher compared with baseline (ANR: 19.1 versus 16.3, $\mathrm{t}=4.632, \mathrm{df}=20, \mathrm{p}=.0001$; ANBP: 18.7 versus $16.2, \mathrm{t}=6.443, \mathrm{df}=36, \mathrm{p}=.0001)$.

shows the survival curve per diagnostic subgroup. The BN group had the shortest median time to recovery at 2.8 years compared with the other diagnostic subgroups. The ANR group followed at 3.3 years, and the ANBP group reached this point after 4.4 years. Thus, compared with the BN group, the median time to recovery of the ANBP group was 1.6 times longer. The total group had a median time to recovery of 3.5 years. The survival curves of the ANBP and the BN groups differed significantly (Mantel-Cox Log Rank $=4.559$, $\mathrm{df}=1$, $\mathrm{p}=.03$ ). However, there were no differences found between the survival curves of the ANR and ANBP groups (Mantel-Cox Log Rank $=1.006, \mathrm{df}=1, \mathrm{p}=.316$ ) nor between the ANR and BN groups (Mantel-Cox Log Rank $=0.730, \mathrm{df}=1, \mathrm{p}=.393$ ).

\section{[FIGURE 2]}

\section{Mortality}

Of the 147 cases, one female $(0.7 \%)$, diagnosed with ANR had died by suicide. The death occurred 3 years after detection by the GP.

\section{Remission of Binge Eating and Purging Behaviors}

The analyses on binge eating and purging remission were only performed on the diagnostic subgroups ANBP and BN. The median survival time for binge eating was for BN 0.8 years and for ANBP 1.4 years. Self-induced vomiting had a median survival time of 1.7 years for $\mathrm{BN}$ and 2.3 years for ANBP.

Laxative use had the longest median survival time of 1.5 years for $\mathrm{BN}$ and 4.1 years for ANBP. The survival time for laxative use was different for ANBP and BN at an alpha level of $\mathrm{p}<.10$ (Mantel-Cox Log Rank $=2.811, \mathrm{df}=1, \mathrm{p}=.09$ ).

\section{Mental Health Treatment}

The ANBP group had the highest referral rate to mental health care (assessment at detection) of $72 \%$ (34/47 patients). In total, $48 \%$ (14/28) of the patients with ANR and $61 \%$ $(43 / 71)$ of the patients with $\mathrm{BN}$ were referred to mental health care. There was no difference 
Son, G.E. van, Hoeken, D. van, Furth, E.F. van, Donker, G.A., Hoek, H.W. Course and outcome off eating disorders in a primary care-based cohort. International Journal of Eating Disorders: 2010, 43(2), 130-138

in outcome between the referred and the nonreferred groups per diagnostic subgroup (ANR: $X^{2}=0.293 \mathrm{df}=1, \mathrm{p}=.59 ;$ ANBP: $\left.X^{2}=1.021, \mathrm{df}=1, \mathrm{p}=.31 ; \mathrm{BN} X^{2}=1.030, \mathrm{df}=1, \mathrm{p}=.31\right)$.

\section{Predictors of Outcome}

Age at detection predicted outcome of AN and BN at follow-up. For AN, the odds ratio (OR) of recovery at follow-up in participants of 19 years and younger versus 20 years and older at baseline was $\mathrm{OR}=4.3(95 \% \mathrm{CI}=1.5-12.1, \mathrm{p}=.005)$. For $\mathrm{BN}$, the effect was significant at the alpha level $\mathrm{p}<.10(\mathrm{OR}=8.2 ; 90 \% \mathrm{CI}=1.38-48.38)$. Thus, patients diagnosed with $\mathrm{AN}$ or $\mathrm{BN}$ who are 19 years or younger at the time of detection are more often recovered at outcome than patients of 20 years or older. Follow-up duration (AN: Wald $=1.47, \mathrm{df}=1, \mathrm{p}=.22 ; \mathrm{BN}:$ Wald $=0.49, \mathrm{df}=1, \mathrm{p}=.48)$, referral to mental health care (AN: Wald $=1.06, \mathrm{df}=1, \mathrm{p}=.30 ; \mathrm{BN}:$ Wald $=0.10, \mathrm{df}=1, \mathrm{p}=.31$ ), BMI (only AN: Wald $=1.21$, $\mathrm{df}=2, \mathrm{p}=.55$ ), and frequency of binge eating (only $\mathrm{BN}$ : Wald $=0.006, \mathrm{df}=2, \mathrm{p}=.99$ ) did not predict outcome.

\section{DISCUSSION}

This study investigated the course and outcome in a nationally representative sample of newly diagnosed patients with eating disorder detected in primary care in the Netherlands during two data collection periods. The main results of the study were that after a mean of 4.8 years of follow-up, $55 \%$ of the patients initially diagnosed with ANR, $57 \%$ of the ANBP, and $61 \%$ of the patients diagnosed with $\mathrm{BN}$ were considered to be recovered.

At follow-up, $17 \%$ of the patients diagnosed with ANR, 23\% with ANBP, and $6 \%$ with BN still met the criteria of the initial eating disorder diagnosis.

Of the patients with BN, an additional $20 \%$ changed diagnostic category to EDNOS (including BED). One female patient (AN) had died by suicide $(0.7 \%)$.

The patients diagnosed with ANBP show the most extended median survival time (the point at which half of the group has reached full recovery) of the three diagnostic groups; compared with the BN group, it takes 1.6 times longer to reach the median survival time. As seen in Figure 2, the contrast in time to recovery is most marked 3 years after detection. A hypothesis about the lon-gest time to recover compared with the other eating disorder subgroups might be that patients diagnosed with ANBP show the highest levels of psychological disturbance compared to patients from the other diagnostic subgroups. Keel et al. ${ }^{29}$ performed a latent class analysis on a group of patients with an eating disorder. One of the classes they found was a group that consisted of patients with AN and BN that used multiple purging methods. Most members of this latent class were diagnosed with the DSMIV as having an ANBP diagnosis. Overall, the members of this group had the highest levels of psychological disturbance.

The higher levels of psychological disturbance in the ANBP diagnostic subgroup might slow down the recovery process.

Diagnostic crossover in this primary care cohort was found to be low compared with other studies.

${ }^{30-32} \mathrm{We}$ found no crossover from ANR to other diagnostic subgroups. We also found no crossover from $\mathrm{BN}$ to either of the AN subgroups. We did find crossover from ANBP to BN (7\%) and to EDNOS (7\%). Perhaps, diagnostic crossover is more common in patients with more severe eating disorder symptoms. This would explain a higher crossover rate that is found in studies that used samples of patients that were treated in psychiatric settings. ${ }^{30}$ The only predictive factor for outcome in this study was age at detection. When a patient is 19 years or younger at the time of detection by the GP, the chance of being recovered at followup for $\mathrm{AN}$ is four times higher and for $\mathrm{BN}$ eight times higher.

Thus, on the basis of our study results, early detection of eating disorders is of major importance.

According to a review on AN that explicitly focused on the relationship between duration of illness, early intervention and outcome it was concluded that a large interval between the 
Son, G.E. van, Hoeken, D. van, Furth, E.F. van, Donker, G.A., Hoek, H.W. Course and outcome off eating disorders in a primary care-based cohort. International Journal of Eating Disorders: 2010, 43(2), 130-138

time of onset and first admission for treatment may be negatively related to outcome of treatment. ${ }^{33}$ Other studies on AN confirm duration of illness as a prognostic factor on outcome. ${ }^{3,4,34}$ However, the reverse, early intervention leads to a better outcome could not be studied because of a lack of appropriate studies. ${ }^{33}$ The author pleads for outcome studies with large, heterogeneous samples of first admissions. For BN, a review shows mixed results, and the authors concluded that the importance of age at onset or presentation for $\mathrm{BN}$ is unclear. ${ }^{35}$ These mixed results were also found in two more recent long-term follow- up studies on BN. In one study, age at onset or presentation had no predictive value on the outcome, ${ }^{36}$ and in the other, a higher age at onset was a significant predictor for the presence of an ED diagnosis at outcome. ${ }^{5}$ Early detection and referral to specialized care means that the disorder will be treated at a less advanced state thus improving the chances of recovery while decreasing overall mortality rates in AN. ${ }^{17}$ The remission order of symptoms for the subgroups ANBP and BN in our study followed a pattern of first binge eating, then selfinduced vomiting and lastly laxative abuse. This is contrary to results in samples that used patients that were treated in psychiatric settings, in which purging behaviors (vomiting, diuretics, and laxative use) are often in remission before binge eating. ${ }^{37}$ This difference might be explained by the clinical focus on the most health threatening symptoms when a person enters treatment. The natural path of symptom remittance may depend on the severity of the underlying maladaptive core beliefs.

There are indications that engaging in inappropriate compensatory behaviors is linked to more disturbed thinking patterns (core beliefs) compared with binge eating. ${ }^{38,39}$ If one assumes that beliefs underlying binge eating are less maladaptive than those which underlie inappropriate compensatory behaviors, it is likely that binge eating behavior is easier to modify and therefore is the first to remit.

\section{Strengths and Limitations}

A major strength of the study was that the sample was derived at the primary care level. To our knowledge, no other follow-up study has been performed at this level of health care. It therefore fills a gap in the literature. ${ }^{7}$ Another strength was the prospective design of the study, by which newly detected patients with an eating disorder were followed from the moment they entered the study.

The study also had its limitations. We obtained information from the GP's and not from the patients themselves. With this method, we were not able to directly assess the specific psychological symptoms. Nevertheless, the GP is a MD who also receives information from several other sources (family and other health care professionals), and this enhances the reliability of the information.

Furthermore, we primarily asked about objective behavior of the patients or about variables that were easily measurable (i.e., BMI). Most information could be extracted from the GP's clinical records, thus previously documented information.

The outcome diagnosis was determined by combining objective data with the judgment of the investigators and GP's and can be considered a "most likely" diagnosis. Finally, the drop-out rate in our study might have biased the results.

However, the main reasons for drop-out in our study were not caused by patient characteristics but by nonresponse of the GP and departure of the patient from the initial GP practice. A review study provided no clear indication that studies with high drop-out rates have better or worse results. ${ }^{3}$ Furthermore, on baseline characteristics, ANR and ANBP showed no differences between the groups for which follow-up data were and were not available. However, the $\mathrm{BN}$ group on which follow-up information was available had a higher BMI.

To conclude, the findings of this primary care cohort show that the diagnosis ANBP has the most extended time to recovery. Younger age at detection predicts a more favorable outcome at follow-up for $\mathrm{AN}$ and $\mathrm{BN}$, which emphasizes the importance of early detection of eating disorders. 
Son, G.E. van, Hoeken, D. van, Furth, E.F. van, Donker, G.A., Hoek, H.W. Course and outcome of eating disorders in a primary care-based cohort. International Journal of Eating Disorders:

2010, 43(2), 130-138

On the basis of the low crossover pattern, and the significant difference in survival curves between the $\mathrm{AN}$ and $\mathrm{BN}$ groups, our study offers support for maintaining the diagnostic distinction between AN and BN as currently is the case in the DSM-IV.

The authors thank the Netherlands Institute for Health Services Research (NIVEL) and the participating GP's for their efforts in collecting the data.

\section{REFERENCES}

1. Hoek HW. Incidence, prevalence and mortality of anorexia nervosa and other eating disorders. Curr Opin Psychiatry 2006;19:389-394.

2. Harris EC, Barraclough B. Excess mortality of mental disorders.

Br J Psychiatry 1998;173:11-53.

3. Steinhausen HC. The outcome of anorexia nervosa in the 20th century. Am J Psychiatry 2002;159:1284-1293.

4. Fichter MM, Quadflieg N, Hedlund S. Twelve-year course and outcome predictors of anorexia nervosa. Int J Eat Disord 2006;39:87-100.

5. Fichter MM, Quadflieg N. Twelve-year course and outcome of bulimia nervosa. Psychol Med 2004;34:1395-1406.

6. Keel PK, Mitchell JE, Miller KB, Davis TL, Crow SJ. Long-term outcome of bulimia nervosa. Arch Gen Psychiatry 1999;56:63-69.

7. Berkman ND, Lohr KN, Bulik CM. Outcomes of eating disorders: A systematic review of the literature. Int J Eat Disord 2007;40:293-309.

8. Hoek HW, van Hoeken D. Review of the prevalence and incidence of eating disorders. Int J Eat Disord 2003;34:383-396.

9. Fairburn CG, Welch SL, Norman P, O'Conner ME, Doll HA. Bias and bulimia nervosa: How typical are clinic cases? Am J Psychiatry 1996;153:386-391.

10. Sareen J, Stein MB, Campbell DW, Hassard T, Menec V. The relation between perceived need for mental health treatment, DSM diagnosis, and quality of life: A Canadian populationbased survey. Can J Psychiatry 2005;50:87-94.

11. Meadows G, Burgess P, Bobevski I, Fossey E, Harvey C, Liaw ST.

Perceived need for mental health care: Influences of diagnosis, demography and disability. Psychol Med 2002;32:299-309.

12. Keski-Rahkonen A, Hoek HW, Susser ES, Linna MS, Sihvola E, Raevuori A, et al. Epidemiology and course of anorexia nervosa in the community. Am J Psychiatry 2007;164:1259-1265.

13. Bartelds AIM. Continuous Morbidity Registration Sentinel Stations The Netherlands 1998. Utrecht: NIVEL, 2000.

14. Health Care Information Centre. Health care. In: Dutch Association of Insurers, editor. Dutch Insurance Industry in Figures 2003. The Hague: Dutch Association of Insurers, 2004, pp.124- 132.

15. Bartelds AIM. Continuous Morbidity Registration Sentinel Stations The Netherlands 1995. Utrecht: NIVEL, 1996.

16. Bartelds AIM. Continuous Morbidity Registration Sentinel Stations The Netherlands 1998. Utrecht: Bookbindery Anraad, 2000.

17. Hoek HW, Bartelds AIM, Bosveld JJF, van der Graaf Y, Limpens VEL, Maiwald M, et al. Impact of urbanization on detection rates of eating disorders. Am J Psychiatry 1995;152:1272-1278.

18. Cachelin FM, Maher BA. Is amenorrhea a critical criterion for anorexia nervosa. J Psychosom Res 1998;44:435-440.

19. Garfinkel PE, Lin E, Goering P, Spegg C, Goldbloom DS, Kennedy S, et al. Should amenorrhoea be necessary for the diagnosis of anorexia nervosa? Evidence from a Canadian community sample.

Br J Psychiatry 1996;168:500-506.

20. Watson TL, Andersen AE. A critical examination of the amenorrhea and weight criteria for diagnosing anorexia nervosa. Acta Psychiatr Scand 2003;108:175-182.

21. Abraham SF, Pettigrew B, Boyd C, Russell J, Taylor A. Usefulness of amenorrhoea in the diagnoses of eating disorder patients. J Psychosom Obstet Gynaecol 2005;26:211215. 
Son, G.E. van, Hoeken, D. van, Furth, E.F. van, Donker, G.A., Hoek, H.W. Course and outcome of eating disorders in a primary care-based cohort. International Journal of Eating Disorders: 2010, 43(2), 130-138

22. Roberto CA, Steinglass J, Mayer LE, Attia E, Walsh BT. The clinical significance of amenorrhea as a diagnostic criterion for anorexia nervosa. Int J Eat Disord 2008;41:559563.

23. Kordy H, Kramer B, Palmer RL, Papezova H, Pellet J, Richard M, et al. Remission, recovery, relapse, and recurrence in eating disorders: Conceptualization and illustration of a validation strategy. J Clin Psychol 2002;58:833-846.

24. van Son GE, van Furth EF, Bartelds AIM, Hoek HW, van Hoeken D. Time trends in the incidence of eating disorders: A primary care study in The Netherlands. Int J Eat Disord 2006;39:565- 569.

25. Keel PK, Mitchell JE, Miller KB, Davis TL, Crow SJ. Long-term outcome of bulimia nervosa. Arch Gen Psychiatry 1999;56:63- 69.

26. Ben Tovim DI, Freeman R, Kalucy R, Walker K, Gilchrist P, Esterman A. Outcome in patients with eating disorders: A 5-year study. Lancet 2001;357:1254-1257.

27. Fairburn CG, Cooper Z, Doll HA, Norman P, O'Conner M. The natural course of bulimia nervosa and binge eating disorder in young women. Arch Gen Psychiatry 2000;57:659665 .

28. Vrabel KR, Rosenvinge JH, Hoffart A, Martinsen EW, Ro O. The course of illness following inpatient treatment of adults with longstanding eating disorders: A 5-year followup. Int J Eat Disord 2008;41:224-232.

29. Keel PK, Fichter M, Quadflieg N, Bulik CM, Baxter MG, Thornton L, et al. Application of a latent class analysis to empirically define eating disorder phenotypes. Arch Gen Psychiatry 2004;61:192-200.

30. Eddy KT, Dorer DJ, Franko DL, Tahilani K, Thompson-Brenner H, Herzog DB.

Diagnostic crossover in anorexia nervosa and bulimia nervosa: Implications for DSM-V. Am J Psychiatry 2008;165:245-250.

31. Milos G, Spindler A, Schnyder U, Fairburn CG. Instability of eating disorder diagnoses: Prospective study. Br J Psychiatry 2005;187:573-578.

32. Tozzi F, Thornton LM, Klump KL, Fichter MM, Halmi KA, Kaplan AS, et al. Symptom fluctuation in eating disorders: Correlates of diagnostic crossover. Am J Psychiatry 2005;162:732-740.

33. Schoemaker $\mathrm{C}$. Does early intervention improve the prognosis in anorexia nervosa? A systematic review of the treatment-outcome literature. Int J Eat Disord 1997;21:1-15.

34. Zipfel S, Lowe B, Reas DL, Deter HC, Herzog W. Long-term prognosis in anorexia nervosa: Lessons from a 21-year follow-up study. Lancet 2000;355:721-722.

35. Keel PK, Mitchell J. Outcome in bulimia nervosa. Am J Psychiatry 1997;154:313-321.

36. Reas DL, Williamson DA, Martin CK, Zucker NL. Duration of illness predicts outcome for bulimia nervosa: A long-term followup study. Int J Eat Disord 2000;27:428-434.

37. Clausen L. Time course of symptom remission in eating disorders.

Int J Eat Disord 2004;36:296-306.

38. Dingemans AE, Spinhoven $P$, van Furth EF. Maladaptive core beliefs and eating disorder symptoms. Eat Behav 2006;7:258- 265.

39. Waller G. Schema-level cognitions in patients with binge eating disorder: A case control study. Int J Eat Disord 2003;33:458- 464. 
Son, G.E. van, Hoeken, D. van, Furth, E.F. van, Donker, G.A., Hoek, H.W. Course and outcome of eating disorders in a primary care-based cohort. International Journal of Eating Disorders:

\section{TABLES EN FIGURES}

FIGURE 1 Flowchart response.

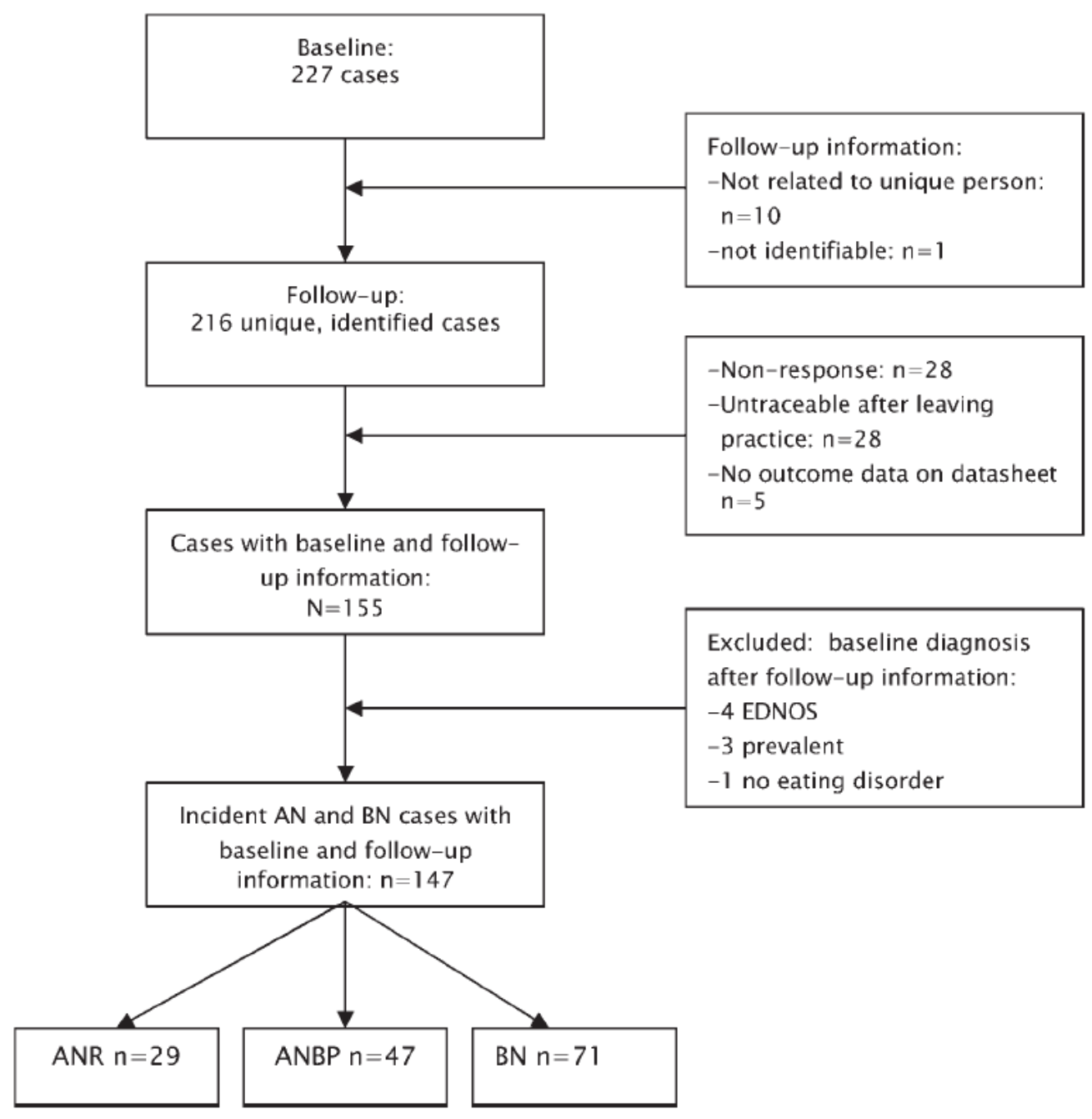

TABLE 1. Baseline characteristics of the sample

\begin{tabular}{lllll}
\hline & ANR $N=29$ & ANBP $N=47$ & BN $N=71$ & ANOVA test and significance \\
\hline \% Female & $93 \%(n=27)$ & $96 \%(n=45)$ & $97 \%(n=69)$ & $F(2,144)=0.43, \mathrm{~ns}$ \\
Age in years (SD) & $22.7(8.4)$ & $22.0(7.6)$ & $28.2(8.4)$ & $F(2,144)=9.807, p<.01$ \\
BMI (SD) & $16.2(1.7)$ & $16.4(1.9)$ & $29.3(7.3)$ & $F(2,135)=107.93, p<.01$ \\
\hline
\end{tabular}


Son, G.E. van, Hoeken, D. van, Furth, E.F. van, Donker, G.A., Hoek, H.W. Course and outcome of eating disorders in a primary care-based cohort. International Journal of Eating Disorders: 2010, 43(2), 130-138

TABLE 2. The outcome per diagnostic subgroup

\begin{tabular}{lccc}
\hline & \multicolumn{3}{c}{ Diagnosis at detection } \\
\cline { 2 - 4 } & ANR $(n=29)$ & ANBP $(n=47)$ & BN $(n=71)$ \\
\hline Outcome & $N(\%)$ & $N(\%)$ & $N(\%)$ \\
Good & $16(55 \%)$ & $27(57 \%)$ & $43(61 \%)$ \\
Intermediate & $6(21 \%)$ & $8(17 \%)$ & $16(22 \%)$ \\
Poor & $6(21 \%)$ & $11(23 \%)$ & $4(6 \%)$ \\
Unknown & $1(3 \%)$ & $1(2 \%)$ & $8(11 \%)$ \\
Diagnosable ED at follow-up & & & \\
ANR & $5(17 \%)$ & 0 & 0 \\
ANBP & 0 & $11(23 \%)$ & 0 \\
BN & 0 & $3(6 \%)$ & $4(6 \%)$ \\
EDNOS & 0 & $3(6 \%)$ & $14(20 \%)$ \\
\hline
\end{tabular}

a Including patients that died

FIGURE 2 Life table (one-minus survival) of recovery rates per diagnostic subgroup.

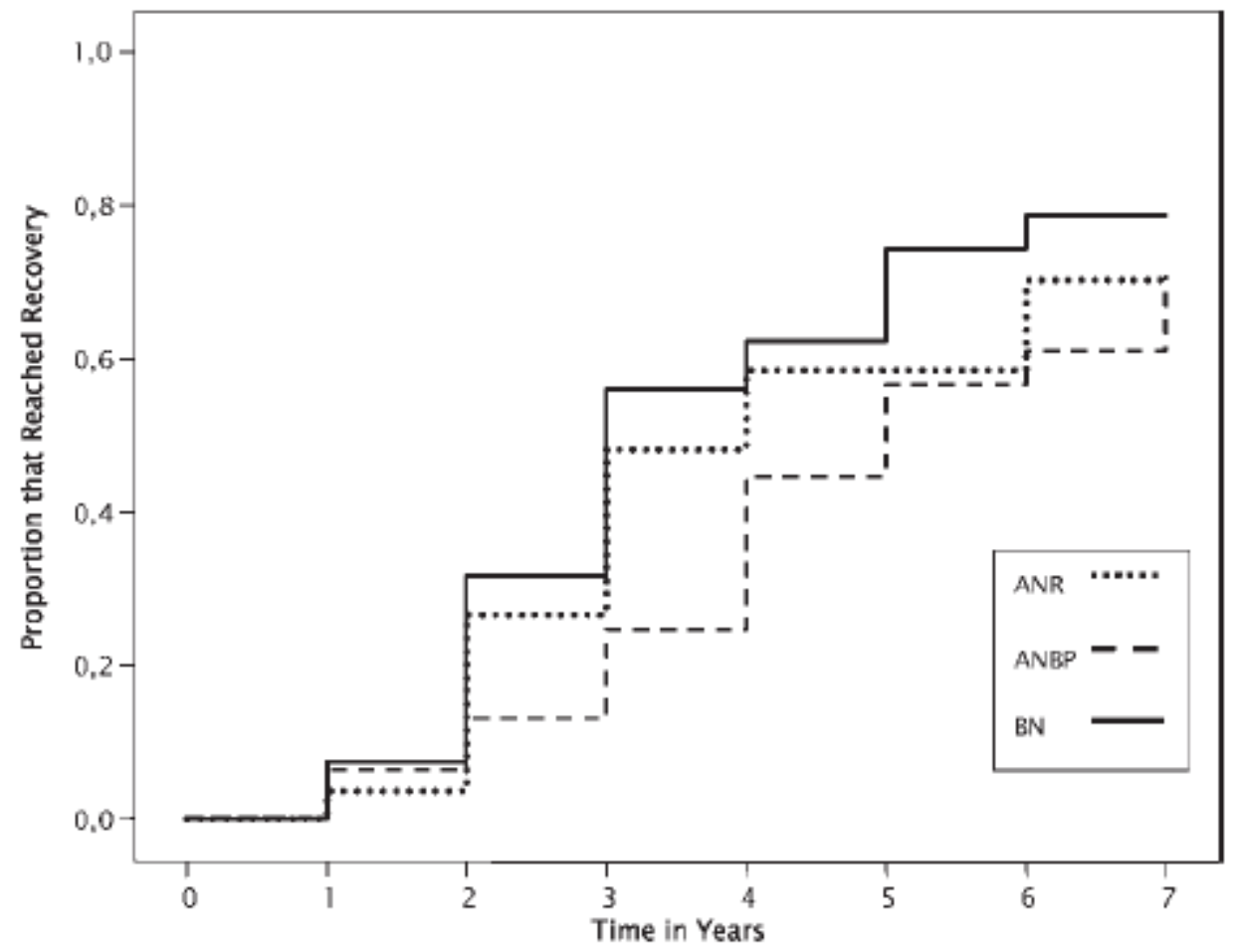

